\title{
Estimation of dielectric properties of clay loam and silty soil with different salinity levels over low frequency range
}

\author{
Virendrakumar N. Patel, Prahalad D. Chaudhary, Vipin A. Rana and \\ Deepak H. Gadani* \\ Department of Physics, University School of Sciences, Ahmedabad 380 009, India
}

\begin{abstract}
The dielectric properties of clay loam and silty soil moistened with various proportions of distilled water and saline solutions over the frequency range from $20 \mathrm{~Hz}$ to $2 \mathrm{MHz}$ were estimated. It was observed that the dielectric constant $\varepsilon^{\prime}$ and dielectric loss $\varepsilon^{\prime \prime}$ increased with increase in volumetric moisture content in the soils. Frequency-dependent dielectric constant $\varepsilon^{\prime}$ and dielectric loss $\varepsilon^{\prime \prime}$ were found to decrease rapidly with increase in frequency. For moist soils, the dielectric loss increased more rapidly with increase in salinity compared to the corresponding dielectric constant. The complex impedance $Z^{*}\left(=Z^{\prime}-J Z^{\prime \prime}\right)$ was also calculated from the measured values of $\varepsilon^{\prime}$ and $\varepsilon^{\prime \prime}$ for the soils. The complex impedance plots $\left(Z^{\prime \prime}\right.$ against $\left.Z^{\prime}\right)$ for clay loamy and silty soils with moisture content of distilled water and saline water solutions revealed that bulk resistance of the soil decreased with increase in salinity in the wet soil, indicating an increase in conductivity of the soil.
\end{abstract}

Keywords: Clay loam and silty soil, dielectric properties, low frequency range, saline water.

SoIL is a complex material, with the micro-macro structure of pore spaces between the soil particles that vary widely with soil particle size and shape, density, salinity, organic matter content and porosity of the soil ${ }^{1}$. Different types of soils have different physical, chemical and electrical properties ${ }^{2}$. Physical properties of the soil consist of sand, silt and clay contents, bulk density, colour as well as porosity. Chemical properties of the soil include macronutrients and micronutrients like $\mathrm{N}, \mathrm{P}, \mathrm{K}, \mathrm{Ca}, \mathrm{Mg}$ and $\mathrm{Fe}, \mathrm{Mn}, \mathrm{Zn}, \mathrm{Cu}$ respectively. Electrical properties of the soil include conductivity, permeability and permittivity (complex dielectric constant). Electrical properties of the soil provide information about moisture content and salinity of the soil, which is useful in many branches of science and technology, agriculture, hydrology, meteorology, etc. The dielectric behaviour of geological mate-

*For correspondence. (e-mail: dhgadani@yahoo.com) rials can provide useful information about the presence of water in the soil, subsurface properties of the soil and characteristics of adsorbed pore fluid on the soil particles $^{3,4}$.

In this study, we have estimated the dielectric properties of two different types of soil with water of different salinities over the frequency range from $20 \mathrm{~Hz}$ to $2 \mathrm{MHz}$ using a Precision LCR meter. We have used clay loam and silty soil to estimate the effect of distilled water, $10,000 \mathrm{ppm}$ saline water, $20,000 \mathrm{ppm}$ saline water, $30,000 \mathrm{ppm}$ saline water and Dwarka Sea bank saline water $(38,270 \mathrm{ppm})$ with different moisture content in the soils. It has been observed by researchers that the dielectric constant $\varepsilon^{\prime}$ and dielectric loss $\varepsilon^{\prime \prime}$ increase with decrease in frequency over the radiofrequency range ${ }^{5-9}$.

\section{Materials and method}

The experimental set-up and methodology given by Gadani et $a l .{ }^{8}$ and Chaudhary et al. ${ }^{10}$ have been followed in this study to obtain the electrical properties.

\section{Sample preparation}

The soil samples were collected from two different locations, namely Undai (Bhabhar-Banaskantha, Gujarat) and Udhamsingh Nagar (Uttarakhand). Stone and gravel fraction was removed from the soil samples, and the remaining finer grained part of the soil samples was oven-dried at $110^{\circ} \mathrm{C}$ for $24 \mathrm{~h}$. Then distilled water was added to the soil in different proportions and allowed to saturate for $24 \mathrm{~h}$. To observe the effect of saline water on the dielectric properties of the soil, saline solutions of 10,000 , 20,000 and $30,000 \mathrm{ppm}$ were prepared by adding $\mathrm{NaCl}$ (AR-grade) in proportions of 10, 20 and $30 \mathrm{~g} / 1$ of distilled water respectively. Saline water $(38,270 \mathrm{ppm})$ was also collected from the Dwarka Sea bank. The saline water was mixed with soils in different proportions and allowed to saturate for $24 \mathrm{~h}$. 
Table 1. Texture of soil samples and their analysis. The analysis of Dwarka Sea bank saline water is also shown

\begin{tabular}{lccc}
\hline Textures & $\begin{array}{c}\text { Undai (Bhabhar, Banaskantha, } \\
\text { Gujarat) }\end{array}$ & $\begin{array}{c}\text { Udhamsingh Nagar } \\
\text { (Uttarakhand) }\end{array}$ & $\begin{array}{c}\text { Dwarka Sea bank water } \\
\text { (Dwarka, Gujarat) }\end{array}$ \\
\hline Sand & $46.8 \%$ & $34 \%$ & - \\
Silt & $20.9 \%$ & $63 \%$ & - \\
Clay & $32.3 \%$ & $3 \%$ & - \\
Soil type & Clay loam & Silty & - \\
Dry density $\left(\mathrm{g} / \mathrm{cm}^{3}\right)$ & 1.4043 & 1.4113 & - \\
Wt & 0.2592 & 0.1946 & - \\
Porosity & 0.4701 & 0.4674 & 38,270 \\
TDS/ppm (salinity) & 124 & - & 7.34 \\
pH at $25^{\circ} \mathrm{C}$ & 7.91 & - & $500(\mathrm{mg} / \mathrm{l})$ \\
Calcium & $15(\mathrm{ppm})$ & - & $11,150(\mathrm{mg} / 1)$ \\
Sodium & $14(\mathrm{ppm})$ & - & $20,000(\mathrm{mg} / 1)$ \\
Chloride & $36(\mathrm{ppm})$ & - & $1,500(\mathrm{mg} / 1)$ \\
Magnesium & $6(\mathrm{ppm})$ & - & $800(\mathrm{mg} / 1)$ \\
Potassium & $1.1(\mathrm{ppm})$ & - & $3680(\mathrm{mg} / \mathrm{l})$ \\
Sulphate & $9(\mathrm{ppm})$ & - & 65,500 \\
Electrical conductivity $\left(\mathrm{mm}^{3} / \mathrm{cm}\right)$ & $190(\mathrm{ppm})$ & - & $7500(\mathrm{mg} / \mathrm{l})$ \\
Total hardness $\left(\mathrm{as}_{3}\right)$ & - & - & $1600(\mathrm{mg} / \mathrm{l})$ \\
Total alkalinity $\left(\mathrm{CaCO}_{3}\right)$ & - & $\mathrm{NA}$ & $22^{\circ} 14^{\prime} 06.9^{\prime \prime} \mathrm{N}$ \\
Latitude & $24^{\circ} 01^{\prime} 47.1^{\prime \prime} \mathrm{N}$ & $\mathrm{NA}$ & $68^{\circ} 57^{\prime} 54.3^{\prime \prime} \mathrm{E}$ \\
Longitude & $71^{\circ} 38^{\prime} 15.7^{\prime \prime} \mathrm{E}$ &
\end{tabular}

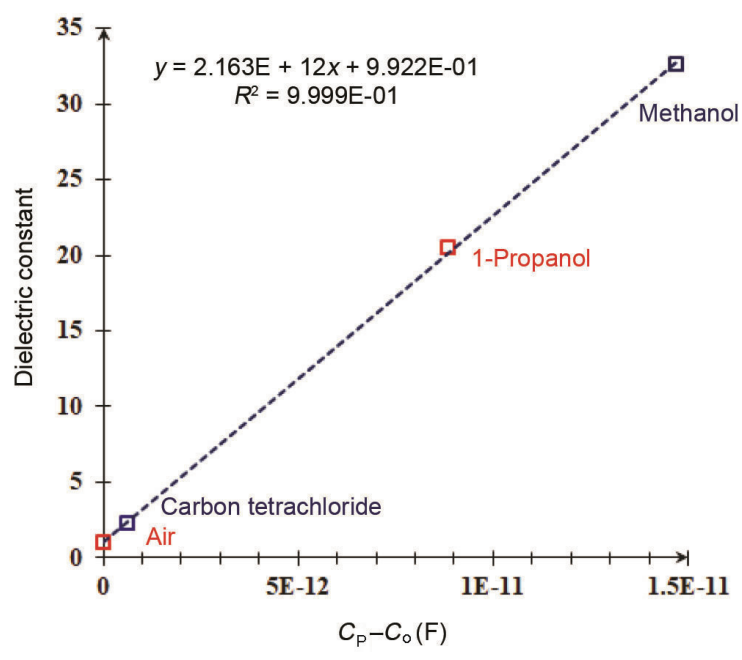

Figure 1. Dielectric constant plotted against $C_{\mathrm{P}}-C_{\mathrm{o}}$ in $\mathrm{F}$.

The gravimetric moisture content $\left(W_{\mathrm{m}}\right)$ and volumetric moisture content $\left(W_{\mathrm{v}}\right)$ in the soil were calculated using formula as follows ${ }^{8}$

$$
\begin{aligned}
& W_{\mathrm{m}}=\frac{\text { Weight of wet soil }- \text { Weight of dry soil }}{\text { Weight of dry soil }}, \\
& W_{\mathrm{v}}=\rho_{\text {dry }} \times W_{\mathrm{m}},
\end{aligned}
$$

where $\rho_{\text {dry }}$ is the dry density of the soil.

\section{Physical properties}

The texture of the soil samples and data on the analysis of saline water of Dwarka Sea coast were obtained from the Vishal Analytical Laboratory, Ahmedabad (Table 1).

\section{Experimental set-up and measurements}

A precision LCR meter (Agilent E-4980A) was used for measurements in the frequency range from $20 \mathrm{~Hz}$ to $2 \mathrm{MHz}$. A standard four-terminal probe (Agilent 16089A) with Kelvin clip was connected to the LCR meter. A coaxial capacitor with four vertical cuts on the outer cylinder was used ${ }^{8}$, which gives almost in situ dielectric properties of the soil sample. The compensation and calibration of the LCR meter and coaxial capacitor were done in two steps: (i) open and (ii) short. Thereafter, the coaxial capacitor was standardized using samples of air, carbon tetrachloride, 1-propanol and methanol, whose dielectric constant is known.

Figure 1 is a plot of dielectric constant against capacitance $\left(C_{\mathrm{P}}-C_{0}\right)$, which is a straight line represented by linear trend line equation

$$
y=0.9922+2.163 \times 10^{12} x
$$

where $x=\left(C_{\mathrm{P}}-C_{0}\right) ; F$ and $y=\varepsilon^{\prime}$ with $R^{2}=0.9999 . C_{\mathrm{P}}$ is the capacitance of capacitor with dielectric, $C_{0}$ the capacitance of capacitor with air as dielectric, $C_{\mathrm{P}}-C_{0}$ is the difference of capacitance. Hence this equation can be used to calculate the dielectric constant $\varepsilon^{\prime}$ of unknown soil samples as

$$
\varepsilon^{\prime}=0.9922+2.163 \times 10^{12}\left(C_{\mathrm{P}}-C_{0}\right),
$$

where $\left(C_{\mathrm{P}}-C_{0}\right)$ is in $F$.

The above equation was used to estimate the dielectric constant of acetone for verification of the result, by measuring $\left(C_{\mathrm{P}}-C_{0}\right)$ for acetone. The estimated value of $\varepsilon^{\prime}$ for acetone is 20.79 at $2 \mathrm{MHZ}$, which agrees well with the literature value of 20.7 (ref. 10), with less than $1 \%$ error. 

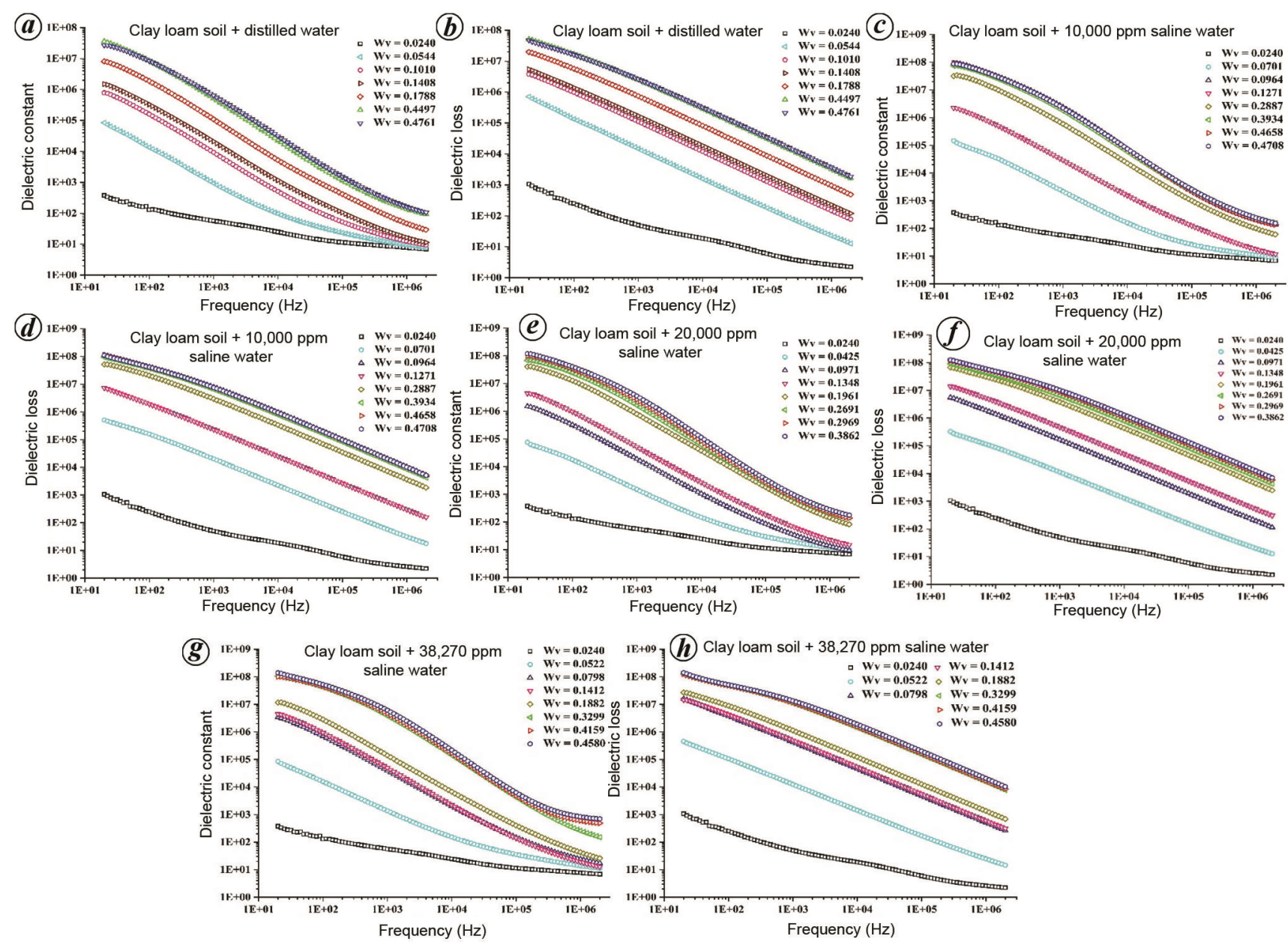

Figure $2 \boldsymbol{a}-\boldsymbol{h}$. Frequency-dependent dielectric constant $\varepsilon^{\prime}$ and dielectric loss $\varepsilon^{\prime \prime}$ of clayey loam soil with different concentrations of Dwarka Sea bank saline water, Dwarka, Gujarat.

The dielectric loss was calculated using equation

$$
\varepsilon^{\prime \prime}=\frac{\varepsilon^{\prime}}{\omega C R}
$$

where we used $C=C_{\mathrm{P}}-C_{0}$ and $R=R_{\mathrm{P}}$ to calculate $\varepsilon^{\prime \prime}$ of the soil samples ${ }^{8,11,12}$.

The frequency-dependent complex conductivity $\sigma^{*}(\omega)$ of the soil systems was calculated as follows

$$
\sigma^{*}(\omega)=\sigma^{\prime}+j \sigma^{\prime \prime}=\omega \varepsilon^{\prime \prime} \varepsilon_{0}+j \omega \varepsilon^{\prime} \varepsilon_{0},
$$

where $\varepsilon_{0}=8.854 \times 10^{-12} \mathrm{~F} / \mathrm{m}$ is the free space dielectric constant.

\section{Results and discussion}

\section{Low frequency dielectric behaviour of wet soil}

Figures 2 and 3 show the variation of frequencydependent dielectric constant $\varepsilon^{\prime}$ and dielectric loss $\varepsilon^{\prime \prime}$ over the low frequency range from $20 \mathrm{~Hz}$ to $2 \mathrm{MHz}$ at room temperature $\left(25^{\circ} \mathrm{C}\right)$ for clayey loam and silty soil respec- tively, with moisture contents of distilled water, saline water and Dwarka Sea water $(38,270 \mathrm{ppm})$. The dielectric constant and dielectric loss increase with decrease in frequency from $2 \mathrm{MHz}$ to $20 \mathrm{~Hz}$. Similar behaviour has been observed by other researchers ${ }^{1,6,8,13-15}$. The large increase in the values of dielectric constant and dielectric loss with decrease in frequency for moist soil is due to the effect of electrode polarization and Maxwell-Wagner polarization $^{16}$. At lower frequency, dipole moment of molecules has sufficient time to accumulate and orient in the direction of the field, because of which charge can be stored and its conductive system is improved. Whereas at high frequency, the required time for orientation and to align in the direction of the electric field is comparatively less. So the dipole orientation does not reach proper alignment in the direction of the field, which can reduce the storing of charge. The dielectric constant of moist soils increases with increase in concentration of salinity, which is due to the presence of $\mathrm{Na}^{+}$cations. The orientation of the ions towards the electrodes contributes to the capacitance, which gives rise to the dielectric constant and dielectric loss. The electrode polarization (EP) occurs 

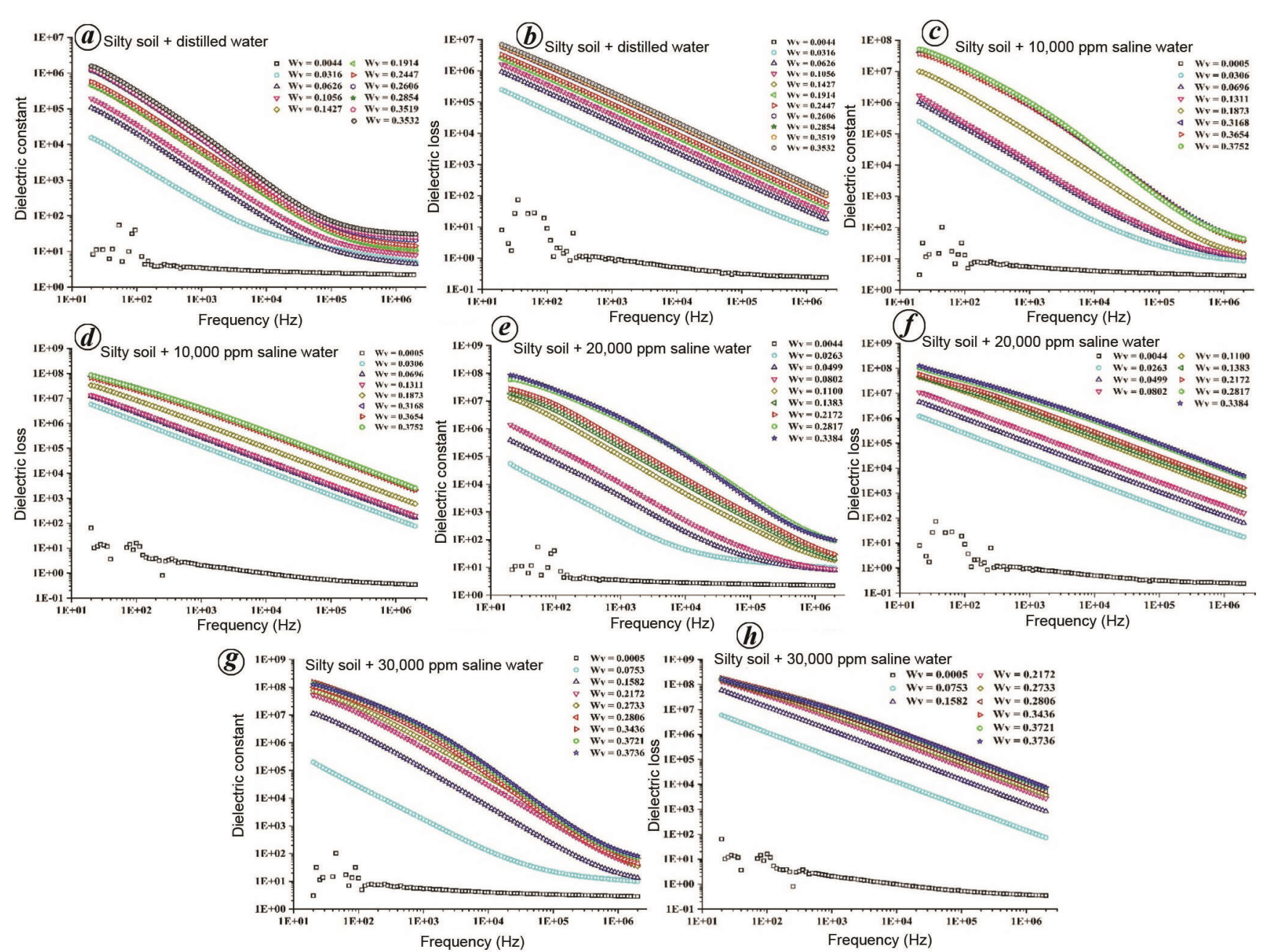

Figure $3 \boldsymbol{a}-\boldsymbol{h}$. Frequency-dependent dielectric constant $\varepsilon^{\prime}$ and dielectric loss $\varepsilon^{\prime \prime}$ of silty soil with different concentrations of 30,000 ppm saline water.

due to the formation of electric double layer (EDL) capacitances as free charges build up at the interface between the electrode surface and the wet soil medium ${ }^{16,17}$. The building-up of free charge at the interfacial boundaries between various components of heterogeneous wet soil medium is responsible for the Maxwell-Wagner polarization. In the EP process, when electric field is applied to the material, anions are attracted towards the positive pole and cations towards the negative pole, due to which the poles face the electrode of opposite charge. In the EP region, the slope of logarithmically varying frequencydependent dielectric constant values close to -1 represent the leakiness of the EDL capacitance to the moving charges, whereas values approaching towards 0 for drier soil as well as for wet soil above $\sim 100 \mathrm{kHz}$ frequency suggest blocking of the charge movement through the layers. From Figures $2 a, b$ and $3 a, b$, it can be observed that at $0.14 \mathrm{~cm}^{3} / \mathrm{cm}^{3}$ moisture content of distilled water in the soils, the dielectric constant and dielectric loss of clay loam soil are higher than those of silty soil over the whole frequency range. Larger area of soil-fluid interface increases spatial polarization at low frequency ${ }^{13}$. Further, clay particles have larger water-holding capacity compared to sand, due to larger surface area to volume ratio. Hence the dielectric constant of clayey loam soil is higher than that of silty soil. Further, clay particles contain more cations and dissolved salts. Hence for same moisture content of distilled water in the soil, the conductivity of clayey loam soil is higher than that of the silty soil, which is responsible for higher dielectric loss in clayey loam soil. It can also be observed that as salinity increases, the dielectric loss increases for the same moisture content in the soils, which is associated with increase in the concentration of $\mathrm{Na}^{+}$ions.

\section{AC conductivity spectra}

As shown in Figures 4 and 5, the real part of conductivity $\sigma$ for wet soil with distilled water increases slowly with increase in frequency. The values of $\sigma$ for wet saline soil increase with increase in frequency and become nearly 

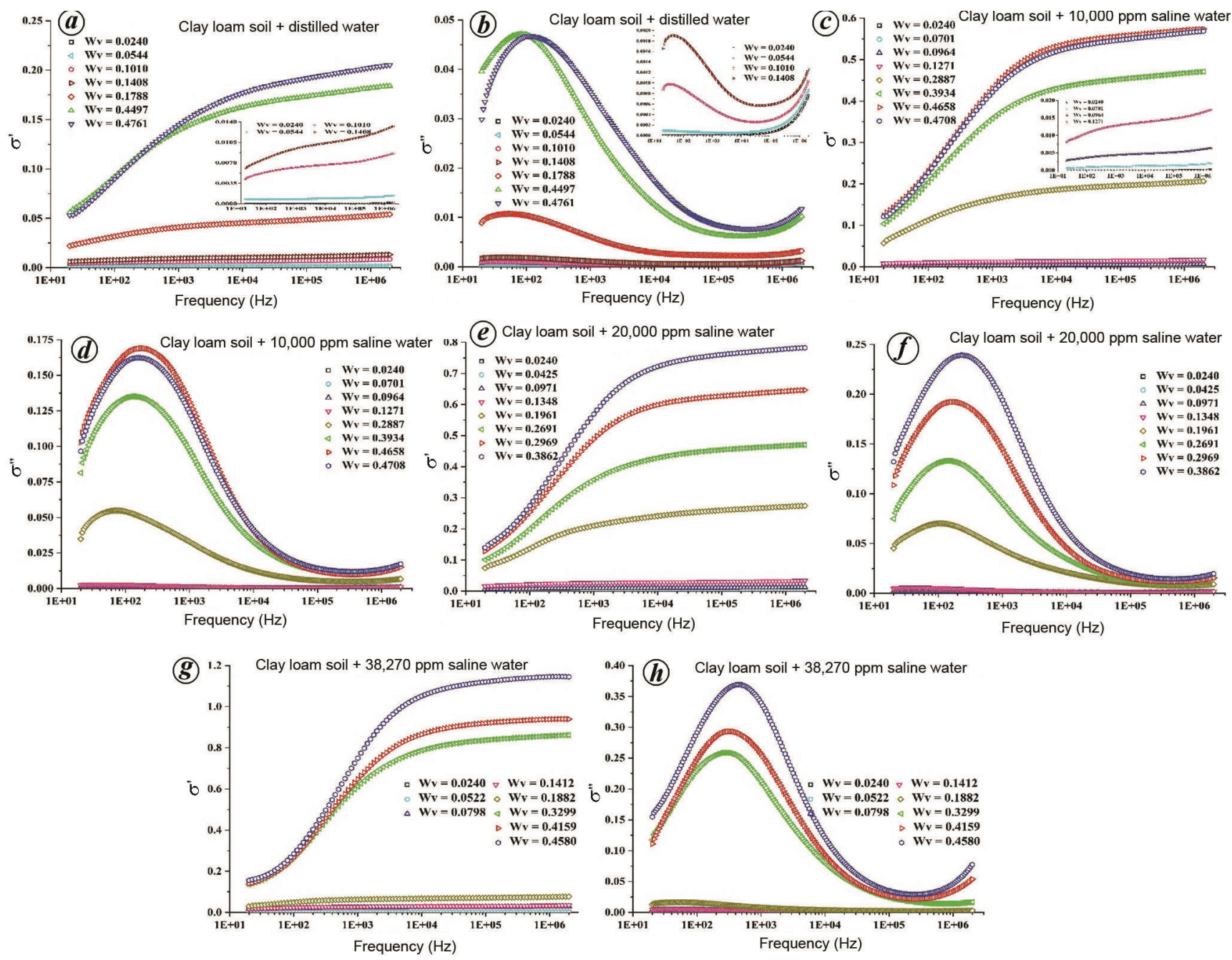

Figure $4 \boldsymbol{a}-\boldsymbol{h}$. Frequency-dependent real conductivity $\left(\sigma^{\prime}\right)$ and imaginary conductivity $\left(\sigma^{\prime \prime}\right)$ of clayey loam soil with different concentrations of saline solutions.

Table 2. Variation of de conductivity of clayey loam soil with moisture content of distilled water and saline solutions

\begin{tabular}{|c|c|c|c|c|c|c|c|}
\hline \multicolumn{2}{|l|}{ Distilled water } & \multicolumn{2}{|c|}{$10,000 \mathrm{ppm}$ saline water } & \multicolumn{2}{|c|}{$20,000 \mathrm{ppm}$ saline water } & \multicolumn{2}{|c|}{$38,270 \mathrm{ppm}$ saline water } \\
\hline $\begin{array}{l}\text { Volumetric } \\
\text { moisture content } \\
\left(\mathrm{cm}^{3} / \mathrm{cm}^{3}\right)\end{array}$ & $\begin{array}{c}\text { DC } \\
\text { conductivity } \\
(\mathrm{S} / \mathrm{m})\end{array}$ & $\begin{array}{l}\text { Volumetric } \\
\text { moisture content } \\
\left(\mathrm{cm}^{3} / \mathrm{cm}^{3}\right)\end{array}$ & $\begin{array}{c}\text { DC } \\
\text { conductivity } \\
(\mathrm{S} / \mathrm{m})\end{array}$ & $\begin{array}{l}\text { Volumetric } \\
\text { moisture content } \\
\left(\mathrm{cm}^{3} / \mathrm{cm}^{3}\right)\end{array}$ & $\begin{array}{c}\text { DC } \\
\text { conductivity } \\
(\mathrm{S} / \mathrm{m})\end{array}$ & $\begin{array}{l}\text { Volumetric } \\
\text { moisture content } \\
\left(\mathrm{cm}^{3} / \mathrm{cm}^{3}\right)\end{array}$ & $\begin{array}{c}\text { DC } \\
\text { conductivity } \\
(\mathrm{S} / \mathrm{m})\end{array}$ \\
\hline 0.024 & $1.18 \times 10^{-6}$ & 0.024 & $1.18 \times 10^{-6}$ & 0.024 & $1.18 \times 10^{-6}$ & 0.024 & $1.18 \times 10^{-6}$ \\
\hline 0.0544 & $7.47 \times 10^{-4}$ & 0.0701 & $5.58 \times 10^{-4}$ & 0.0425 & $3.65 \times 10^{-4}$ & 0.0522 & $5.25 \times 10^{-4}$ \\
\hline 0.1010 & 0.0042 & 0.0964 & 0.0028 & 0.0971 & 0.0062 & 0.0798 & 0.0175 \\
\hline 0.1408 & 0.0060 & 0.1271 & 0.0080 & 0.1348 & 0.0155 & 0.1412 & 0.0162 \\
\hline 0.1788 & 0.0220 & 0.2887 & 0.0569 & 0.1961 & 0.0742 & 0.1882 & 0.0297 \\
\hline 0.4497 & 0.0562 & 0.3934 & 0.1037 & 0.2691 & 0.1007 & 0.3299 & 0.1374 \\
\hline \multirow{2}{*}{0.4761} & 0.0531 & 0.4658 & 0.1234 & 0.2969 & 0.1285 & 0.4159 & 0.1396 \\
\hline & & 0.4708 & 0.1211 & 0.3862 & 0.1398 & 0.458 & 0.1557 \\
\hline
\end{tabular}

constant (plateau region) in the kilo Hertz range in frequency. The plateau region varies with variation in moisture content, salinity of water and the type of soil. The plateau region for clayey loam soil is broader than for the silty soil. Further, as moisture content in the soil increas- es, the width of the plateau region decreases. Also, for the same moisture content, as the salinity of water in the soil increases, the width of the plateau region decreases. The increase in the values of $\sigma^{\prime}$ with increase in frequency, before the plateau region, is evidence for EP effect which 

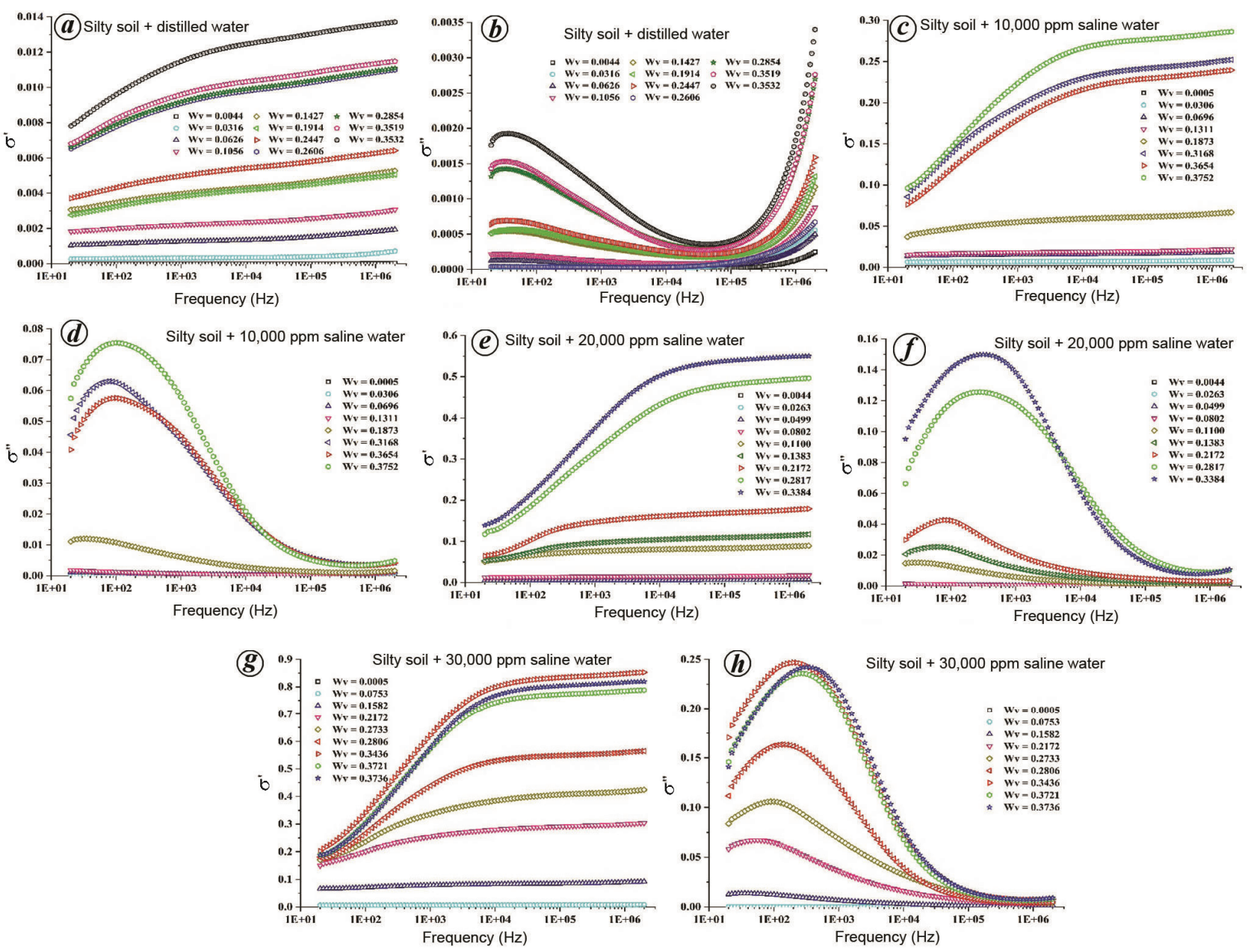

Figure $5 \boldsymbol{a}-\boldsymbol{h}$. Frequency-dependent real conductivity $\left(\sigma^{\prime}\right)$ and imaginary conductivity $\left(\sigma^{\prime \prime}\right)$ of silty soil with different concentrations of water solutions.

masks the ionic conduction of the bulk material ${ }^{18}$. The EP phenomenon occurs due to the formation of EDLs (also known as blocking layers) by the free charges that build up at the interface between the wet soil and metallic electrode surfaces ${ }^{19}$.

\section{Variation of Ohmic $\left(\sigma_{d c}\right)$ conductivity of soils with moisture content of distilled water and saline solutions}

The electrical conductivity of the soil can provide qualitative information about the material ${ }^{3}$. The dc conductivity $\sigma_{\mathrm{dc}}$ represents the number of produced/introduced mobile charge carriers in the materials ${ }^{8}$. Tables 2 and 3 show the variation of de conductivity of clayey loam and silty soil samples with volumetric moisture content of distilled water and saline water respectively. It can be observed from the tables that the dc conductivity of both soils increases by one order of magnitude with increase in moisture content up to saturation level in the soils. The $\sigma_{\mathrm{dc}}$ values for the soil with distilled water as moisture is lower than the mixture of soil with saline water. Further, as salinity increases, the dc conductivity of the soil increases. The observed trend for a given moisture content in the soil is

$$
\begin{aligned}
& \sigma_{\mathrm{dc}(\text { soil }+ \text { distilled water })}<\sigma_{\mathrm{dc}(\text { soil }+10,000 \mathrm{ppm} \text { saline water })}< \\
& \sigma_{\mathrm{dc}(\text { soil }+20,000 \text { ppm saline water })}<\sigma_{\mathrm{dc}(\text { soil }+38,270 \text { ppm saline water })}
\end{aligned}
$$

In the wet soil medium, increase in ionic conductivity is associated with the number of mobile charge carriers introduced/produced with increase in water content in the soil ${ }^{17}$. According to Dobson et al. ${ }^{20}$, the adsorbed cations are tightly held with negatively charged dry soil particles, mainly clay. Excess amount of cations, above the required value to satisfy the surface charge density $\sigma$ of the soil particles, is present in the dry soil as salt precipitate. When water is mixed with soil, the salt precipitates dissolve in the water increasing conductivity of the soil ${ }^{8}$. Thus, the dc conductivity of clayey loam soil is higher than that of silty soil, because of higher clay content in the former soil. Saline water contains a high concentration of dissolved salts. When saline water is mixed with the soils, the salts of the saline water add to the dissolved 

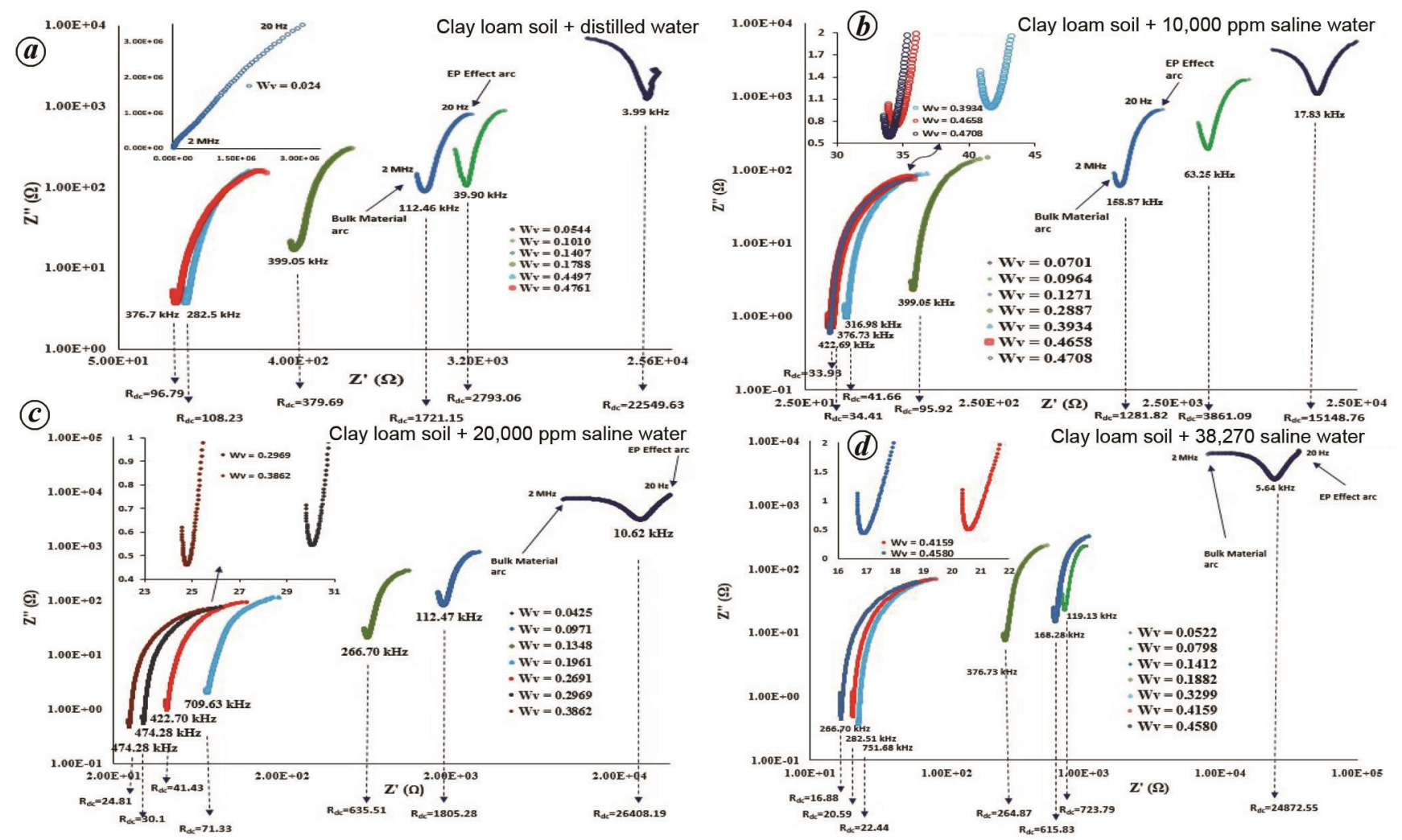

Figure $6 \boldsymbol{a}-\boldsymbol{d}$. Plot of $Z^{\prime \prime}$ against $Z^{\prime}$ for different moisture content of distilled water and saline solutions in clay loam soil.

Table 3. Variation of de conductivity of silty soil with moisture content of distilled water and saline solutions

\begin{tabular}{|c|c|c|c|c|c|c|c|}
\hline \multicolumn{2}{|l|}{ Distilled water } & \multicolumn{2}{|c|}{$10,000 \mathrm{ppm}$ saline water } & \multicolumn{2}{|c|}{20,000 ppm saline water } & \multicolumn{2}{|c|}{$30,000 \mathrm{ppm}$ saline water } \\
\hline $\begin{array}{l}\text { Volumetric } \\
\text { moisture content } \\
\left(\mathrm{cm}^{3} / \mathrm{cm}^{3}\right)\end{array}$ & $\begin{array}{c}\text { DC } \\
\text { conductivity } \\
(\mathrm{S} / \mathrm{m})\end{array}$ & $\begin{array}{c}\text { Volumetric } \\
\text { moisture content } \\
\left(\mathrm{cm}^{3} / \mathrm{cm}^{3}\right)\end{array}$ & $\begin{array}{c}\mathrm{DC} \\
\text { conductivity } \\
(\mathrm{S} / \mathrm{m})\end{array}$ & $\begin{array}{c}\text { Volumetric } \\
\text { moisture content } \\
\left(\mathrm{cm}^{3} / \mathrm{cm}^{3}\right)\end{array}$ & $\begin{array}{c}\mathrm{DC} \\
\text { conductivity }(\mathrm{S} / \mathrm{m})\end{array}$ & $\begin{array}{c}\text { Volumetric } \\
\text { moisture content } \\
\quad\left(\mathrm{cm}^{3} / \mathrm{cm}^{3}\right)\end{array}$ & $\begin{array}{c}\mathrm{DC} \\
\text { conductivity } \\
(\mathrm{S} / \mathrm{m})\end{array}$ \\
\hline 0.0044 & $4.27 \times 10^{-8}$ & 0.0005 & $7.15 \times 10^{-8}$ & 0.0044 & $4.27 \times 10^{-8}$ & 0.0005 & $7.15 \times 10^{-8}$ \\
\hline 0.0316 & $2.96 \times 10^{-4}$ & 0.0306 & 0.0064 & 0.0263 & 0.0014 & 0.0753 & 0.0064 \\
\hline 0.0626 & 0.0010 & 0.0696 & 0.0120 & 0.0499 & 0.0049 & 0.1582 & 0.0660 \\
\hline 0.1056 & 0.0018 & 0.1311 & 0.0148 & 0.0802 & 0.0073 & 0.2172 & 0.1499 \\
\hline 0.1427 & 0.0031 & 0.1873 & 0.0369 & 0.11 & 0.0497 & 0.2733 & 0.1706 \\
\hline 0.1914 & 0.0028 & 0.3168 & 0.0856 & 0.1383 & 0.0526 & 0.2806 & 0.1803 \\
\hline 0.2447 & 0.0037 & 0.3654 & 0.0761 & 0.2172 & 0.0644 & 0.3436 & 0.2021 \\
\hline 0.2606 & 0.0065 & 0.3752 & 0.0962 & 0.2817 & 0.1172 & 0.3721 & 0.1890 \\
\hline 0.2854 & 0.0066 & & & 0.3384 & 0.1386 & 0.3736 & 0.1879 \\
\hline 0.3519 & 0.0068 & & & & & & \\
\hline 0.3532 & 0.0078 & & & & & & \\
\hline
\end{tabular}

Table 4. Variation of $R_{\mathrm{dc}}$ for clayey loam soil with moisture content of distilled water and saline solutions

\begin{tabular}{|c|c|c|c|c|c|c|c|}
\hline \multicolumn{2}{|l|}{ Distilled water } & \multicolumn{2}{|c|}{$10,000 \mathrm{ppm}$ saline water } & \multicolumn{2}{|c|}{$20,000 \mathrm{ppm}$ saline water } & \multicolumn{2}{|c|}{$38,270 \mathrm{ppm}$ saline water } \\
\hline $\begin{array}{l}\text { Volumetric moisture } \\
\text { content }\left(\mathrm{cm}^{3} / \mathrm{cm}^{3}\right)\end{array}$ & $R_{\mathrm{dc}}(\Omega)$ & $\begin{array}{l}\text { Volumetric moisture } \\
\text { content }\left(\mathrm{cm}^{3} / \mathrm{cm}^{3}\right)\end{array}$ & $R_{\mathrm{dc}}(\Omega)$ & $\begin{array}{l}\text { Volumetric moisture } \\
\text { content }\left(\mathrm{cm}^{3} / \mathrm{cm}^{3}\right)\end{array}$ & $R_{\mathrm{dc}}(\Omega)$ & $\begin{array}{l}\text { Volumetric moisture } \\
\text { content }\left(\mathrm{cm}^{3} / \mathrm{cm}^{3}\right)\end{array}$ & $R_{\mathrm{dc}}(\Omega)$ \\
\hline 0.0544 & 22549.63 & 0.0701 & 15148.76 & 0.0425 & 26408.19 & 0.0522 & 24872.55 \\
\hline 0.101 & 2793.06 & 0.0964 & 3861.09 & 0.0971 & 1805.28 & 0.0798 & 723.79 \\
\hline 0.1408 & 1721.15 & 0.1271 & 1281.82 & 0.1348 & 635.51 & 0.1412 & 615.83 \\
\hline 0.1788 & 379.69 & 0.2887 & 95.92 & 0.1961 & 71.33 & 0.1882 & 264.87 \\
\hline 0.4497 & 108.23 & 0.3934 & 41.66 & 0.2691 & 41.43 & 0.3299 & 22.44 \\
\hline 0.4761 & 96.79 & 0.4658 & 34.41 & 0.2969 & 30.10 & 0.4159 & 20.59 \\
\hline & & 0.4708 & 33.93 & 0.3862 & 24.81 & 0.458 & 16.88 \\
\hline
\end{tabular}



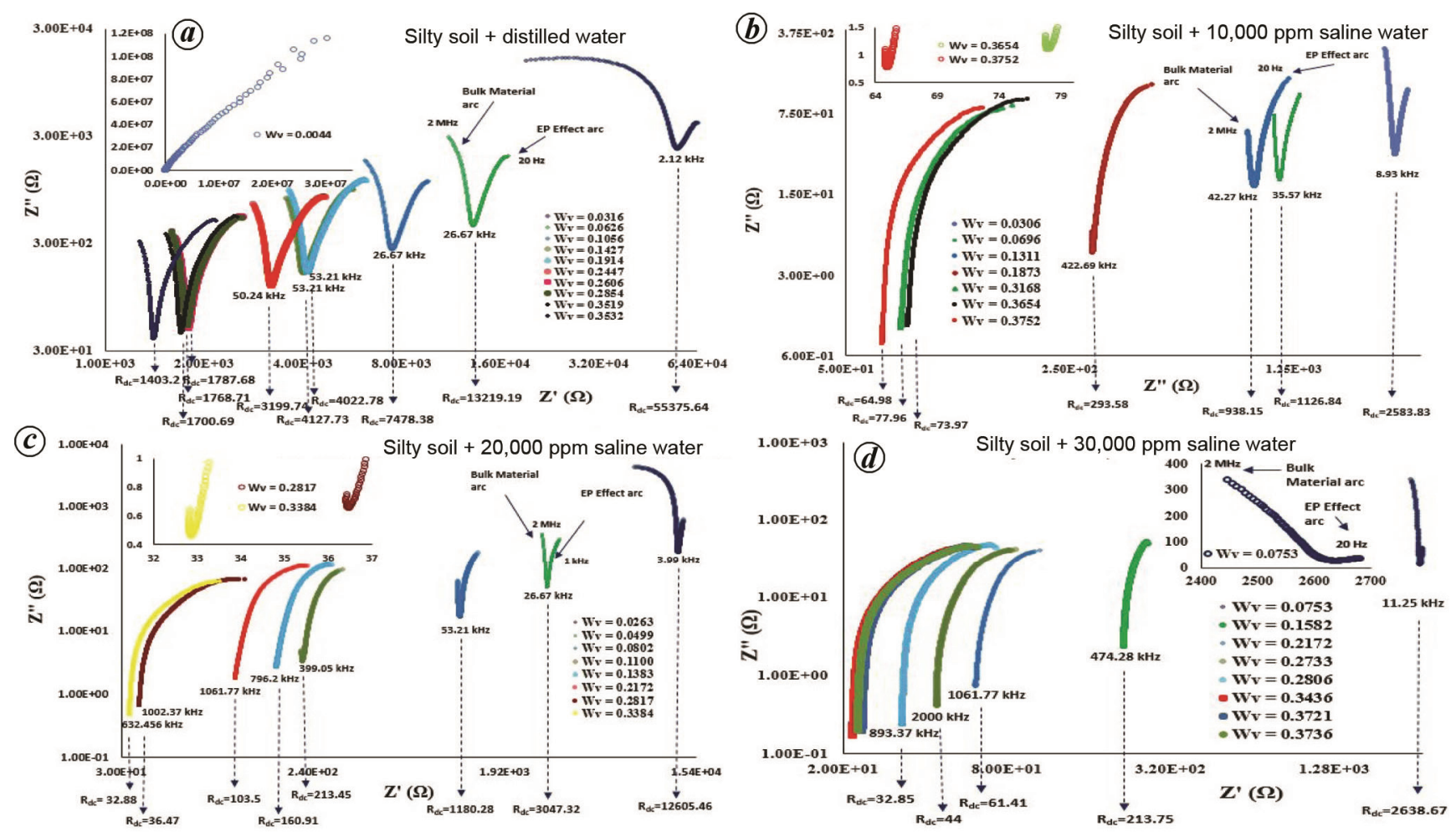

Figure $7 \boldsymbol{a}-\boldsymbol{d}$. Plot of $Z^{\prime \prime}$ against $Z^{\prime}$ for different moisture content of distilled water in clay loam soil.

Table 5. Variation of $R_{\mathrm{dc}}$ for the silty soil with various moisture content of distilled water, and saline solutions in the soil

\begin{tabular}{|c|c|c|c|c|c|c|c|}
\hline \multicolumn{2}{|l|}{ Distilled water } & \multicolumn{2}{|c|}{$10,000 \mathrm{ppm}$ saline water } & \multicolumn{2}{|c|}{$20,000 \mathrm{ppm}$ saline water } & \multicolumn{2}{|c|}{$30,000 \mathrm{ppm}$ saline water } \\
\hline $\begin{array}{l}\text { Volumetric moisture } \\
\text { content }\left(\mathrm{cm}^{3} / \mathrm{cm}^{3}\right)\end{array}$ & $R_{\mathrm{dc}}(\Omega)$ & $\begin{array}{l}\text { Volumetric moisture } \\
\text { content }\left(\mathrm{cm}^{3} / \mathrm{cm}^{3}\right)\end{array}$ & $R_{\mathrm{dc}}(\Omega)$ & $\begin{array}{l}\text { Volumetric moisture } \\
\text { content }\left(\mathrm{cm}^{3} / \mathrm{cm}^{3}\right)\end{array}$ & $R_{\mathrm{dc}}(\Omega)$ & $\begin{array}{l}\text { Volumetric moisture } \\
\text { content }\left(\mathrm{cm}^{3} / \mathrm{cm}^{3}\right)\end{array}$ & $R_{\mathrm{dc}}(\Omega)$ \\
\hline 0.0316 & $55,400.00$ & 0.0306 & $2,583.83$ & 0.0263 & $12,605.46$ & 0.0753 & 2638.67 \\
\hline 0.0626 & $13,219.19$ & 0.0696 & $1,126.84$ & 0.0499 & 3047.32 & 0.1582 & 213.75 \\
\hline 0.1056 & 7478.38 & 0.1311 & 938.15 & 0.0802 & 1180.28 & 0.2172 & 61.41 \\
\hline 0.1427 & 4022.78 & 0.1873 & 293.58 & 0.1100 & 213.45 & 0.2733 & 44.00 \\
\hline 0.1914 & 4127.73 & 0.3168 & 73.97 & 0.1383 & 160.91 & 0.2806 & 32.85 \\
\hline 0.2447 & 3199.74 & 0.3654 & 77.96 & 0.2172 & 103.5 & 0.3436 & 21.56 \\
\hline 0.2606 & 1787.68 & 0.3752 & 64.98 & 0.2817 & 36.47 & 0.3721 & 23.32 \\
\hline 0.2854 & 1768.71 & & & 0.3384 & 32.88 & 0.3736 & 22.39 \\
\hline 0.3519 & 1700.69 & & & & & & \\
\hline 0.3532 & 1403.20 & & & & & & \\
\hline
\end{tabular}

precipitate salts of clay already present in the soil, due to which the conductivity of clayey loam soil increases further. Modi et al..$^{21}$ observed that the conductivity of pure water is lower compared to saline water. As salinity increases the conductivity also increases, and hence dc conductivity of the soil increases with increase in salinity in the water.

\section{Complex impedance spectra and $R_{d c}$}

To analyse the bulk material effect and EP effect for different moisture content of distilled water and saline water on the soils, the complex impedance plane plots $Z^{\prime \prime}$ against $Z^{\prime}$ were plotted for the soil samples. Figures 6 and
7 show the complex impedance plane plots ( $Z^{\prime \prime}$ against $\left.Z^{\prime}\right)$ of clayey loam soil and silty soil for different moisture content of distilled water and saline water of different salinities. For lower moisture content in the soils, mainly the bulk material effect was observed, corresponding to upper frequency arc. As moisture content in the soil increased, along with bulk material effect (upper frequency arc, to the left of $Z_{\text {minimum }}^{\prime \prime}$ ), the EP effect (lower frequency arc, to the right of $Z_{\text {minimum }}^{\prime \prime}$ ) was also observed, separated by minimum values of $Z^{\prime \prime}$. The frequency corresponding to these minimum values of $Z^{\prime \prime}$ separating the bulk material effect and EP effect, represents the EP relaxation frequency $f_{\mathrm{EP}}$. This can be used to calculate the EP relaxation time $\tau_{\mathrm{EP}}=\left(2 \pi f_{\mathrm{EP}}\right)^{-1}$. The extrapolated intercept on the $Z^{\prime}$ axis corresponding to $Z_{\min }^{\prime \prime}$ is useful for 


\section{RESEARCH ARTICLES}

the estimation of the dc bulk resistance $R_{\mathrm{dc}}$, also denoted as $R_{\mathrm{b}}$ of the dielectric material ${ }^{17}$. As the moisture content in the soils increases, the corresponding $R_{\mathrm{dc}}$ values decrease. Further, it can be observed from the figures that as the salinity in the soil increases the $R_{\mathrm{dc}}$ values decrease, which confirms that the conductivity of the soils increases with increase their salinity.

Tables 4 and 5 show the values of $R_{\mathrm{dc}}$ for clayey loam and silty soil respectively. From the tables, it can be observed that with increase in moisture content in the soil, the $R_{\mathrm{dc}}$ values decrease rapidly. The $R_{\mathrm{dc}}$ value at the $0.14 \mathrm{~cm}^{3} / \mathrm{cm}^{3}$ moisture content for distilled water is higher than that of Dwarka Sea water. Thus, the $R_{\mathrm{dc}}$ value decreases with increase in salinity of the soil. Similar results were observed for silty soil. The value of $\tau_{\mathrm{EP}}$ at moisture content of $0.14 \mathrm{~cm}^{3} / \mathrm{cm}^{3}$ for clay loam soil with distilled water was lower than that for the silty soil with distilled water, the higher $\tau_{\mathrm{EP}}$ values depicting larger time taken by the EDL for charging and discharging ${ }^{17}$. We can conclude that the charging or discharging time for clay loam soil is less than that for silty soil, which contributes to the dielectric constant and dielectric loss. This may be one of the reasons for higher dielectric constant of clayey loam than silty soil.

\section{Conclusion}

From the results of this study, the following conclusions have been derived: (1) The dielectric constant and dielectric loss of the soil increase with decrease in the frequency from $2 \mathrm{MHz}$ to $20 \mathrm{~Hz}$. (2) The dielectric constant $\varepsilon^{\prime}$ and dielectric loss $\varepsilon^{\prime \prime}$ of clayey loam soil is higher than that of silty soil over the whole frequency range for the same moisture. (3) The values of $\sigma$ for wet saline soil increase with increase in frequency. (4) As the salinity of the soil increases the $R_{\mathrm{dc}}$ value decreases, which confirms that conductivity of the soil increases with increase in its salinity.

1. Campbell, J. E., Dielectric properties and influence of conductivity in soils at one to fifty megahertz. Soil Sci. Soc. Am. J., 1990, 54, 332-341.

2. Ahire, D. V., Chaudhari, P. R., Ahire, V. D. and Patil, A. A., Correlations of electrical conductivity and dielectric constant with physico-chemical properties of black soils. Int. J. Sci. Res. Publ., 2013, 3, 1-16

3. Kaya, A. and Fang, H., Identification of contaminated soils by dielectric constant and electrical conductivity. J. Environ. Eng., 1997, 123, 169-177.

4. Li, C., Tercier, P. and Knight, R., Effect of sorbed oil on the dielectric properties of sand and clay. Water Resour. Res., 2001, 37, 1783-1793.

5. Chaudhary, P. D., Patel, V. N., Pandit, T. R., Rana, V. A., Vyas, A. D. and Gadani, D. H., Measurement of dielectric properties of moist and fertilized soil at radio frequencies. Int. J. Sci. Res. Rev., 2018, 7, 358-373

6. Bobrov, P. P., Belyaeva, T. A. and Kroshka, E. S., Combined dielectric model of sandy soils in the frequency range from $10 \mathrm{kHz}$ to $8 \mathrm{GHz}$. J. Appl. Geophys., 2018, 159, 616-620.
7. Belyaeva, T. A., Bobrov, P. P., Kroshka, E. S. and Repin, A. V., Complex dielectric permittivity of saline soils and rocks at frequencies from $10 \mathrm{kHz}$ to $8 \mathrm{GHz}$. In Prog. Electromagn. Res. Symp., St Petersburg, Russia, 22-25 May 2017, pp. 3046-3051.

8. Gadani, D. H., Vyas, A. D. and Rana, V. A., Dielectric properties of wet and fertilized soils at radio frequencies. Indian J. Pure Appl. Phys., 2014, 52, 399-410.

9. Sengwa, R. J., Soni, A. and Ram, B., Dielectric behaviour of shale and calcareous sandstone of Jodhpur region. Indian J. Radio Space Phys., 2004, 33, 329-335.

10. Chaudhary, P. D., Patel, V. N., Rana, V. A. and Gadani, D. H., Dielectric properties of soil mixed with urea fertilizer over $20 \mathrm{~Hz}$ to $2 \mathrm{MHz}$ frequency range. Indian J. Pure Appl. Phys., 2020, 58, 455-464.

11. Hill, N. E., Vaughan, W. E., Price, A. H. and Davies, M., Dielectric Properties and Molecular Behaviour, Van Nostrand Reinhold, London, 1969.

12. Levitskaya, T. M. and Steinberg, B. K., Laboratory of material electrical properties: extending the application of lumped-circuit equivalent models to $1 \mathrm{GHz}$. Radio Sci., 2000, 35, 371-383.

13. Oh, M., Kim, Y. and Park, J., Factors affecting the complex permittivity spectrum of soil at a low frequency range of $1 \mathrm{kHz}-$ 10 MHz. Environ. Geol., 2007, 51, 821-833.

14. Santamarina, J. C. and Fam, M., Dielectric permittivity of soils mixed with organic and inorganic fluids $(0.02 \mathrm{GHz}$ to $1.30 \mathrm{GHz})$. J. Environ. Eng. Geophys., 1997, 2, 37-51.

15. Klein, K. A. and Santamarina, J. C., Electrical conductivity in soils: underlying phenomena. J. Environ. Eng. Geophys., 2003, 8, 263-273.

16. Sengwa, R. J., Choudhary, S. and Sankhla, S., Low frequency dielectric relaxation processes and ionic conductivity of montmorillonite clay nanoparticles colloidal suspension in poly (vinyl pyrrolidone)-ethylene glycol blends. eXPRESS Polym. Lett., 2008, 2, 800-809.

17. Sengwa, R. J., Choudhary, S. and Sankhla, S., Dielectric spectroscopy of hydrophilic polymers-montmorillonite clay nanocomposite aqueous colloidal suspension. Colloids Surf. A, 2009, 336, 79-87.

18. Sengwa, R. J., Choudhary, S. and Sankhla, S., Dielectric dispersion and ionic conduction in hydrocolloids of poly (vinyl alcohol)-poly(ethylene oxide) blend-montmorillonite clay. Indian J. Eng. Mater. Sci., 2009, 16, 395-402.

19. Choudhary, S. and Sengwa, R. J., Dielectric relaxation spectroscopy and ion conduction in poly (ethylene oxide)-blend saltsmontmorillonite nanocomposite electrolytes. Indian J. Pure Appl. Phys., 2011, 49, 204-213.

20. Dobson, M. C., Ulaby, F. T., Hallikainen, M. T. and El-rayes, M. A., Microwave dielectric behavior of wet soil - part II: dielectric mixing models. IEEE Trans. Geosci. Remote Sensing, 1985, GE23, 35-46.

21. Modi, F. M., Vankar, H. P., Pandit, T. R., Rana, V. A., Vyas, A. D. and Gadani, D. H., Variation of complex permittivity of water and saline water solutions over microwave frequency range from $1 \mathrm{GHz}$ to $20 \mathrm{GHz}$. Int. J. Sci. Res. Rev., 2018, 7, 281-291.

ACKNOWLEDGEMENTS. We thank Department of Science and Technology and University Grants Commission, New Delhi for providing financial assistance through DST-FIST (LEVEL-1) project (SR/FST/PSI-001/2006) and DRS-SAP programme grant (No. F.530/10/ DRS/2010(SAP-1)) respectively. We also thank Prof. P. N. Gajjar (Head, Department of Physics, University School of Sciences, Gujarat University, Ahmedabad) for encouragement and support.

Received 28 January 2020; revised accepted 20 October 2020

doi: $10.18520 / \mathrm{cs} / \mathrm{v} 120 / \mathrm{i} 2 / 414-422$ 